\title{
Deliberación, deferencia y Corte Interamericana de Derechos Humanos. El caso Gelman vs Uruguay ${ }^{1}$
}

\section{Deliberation, Deference and Interamerican Court of Human Rights. Case Gelman vs Uruguay}

\author{
José María Sauca Cano ${ }^{2}$ \\ Universidad Carlos III de Madrid (España) \\ ORCID: https://orcid.org/0000-0001-5472-4491
}

Recibido: 27-01-2020

Aceptado: 07-09-2020

\section{Resumen}

El caso Gelman supuso la condena de Uruguay por violación de los derechos al reconocimiento de la personalidad jurídica, a la vida, a la integridad personal y a la libertad personal; a la familia, al nombre, a los derechos de los niños y niñas y a la nacionalidad, a la protección de la familia; a las garantías judiciales y a la protección judicial y por haber incumplido la obligación de adecuar su derecho interno a la Convención Americana sobre Derechos Humanos. Amparado en la legitimidad democrática de los referéndums que convalidaban la Ley de Caducidad, Uruguay ha prorrogado la impunidad de los crímenes de la dictadura no ejecutando la sentencia. El autor critica la validez de estos argumentos exculpatorios de este incumplimiento sobre la base de diversas razones.

\footnotetext{
${ }^{1}$ Este artículo forma parte del proyecto "Construcción de derechos emergentes. Debates para la fundamentación de nuevos parámetros de constitucionalidad" del Ministerio de Ciencia e Innovación de España. (Ref. PID2019-106904RB-I00).

2 (josemaria.sauca@uc3m.es). Profesor Titular y catedrático acreditado de Filosofía del Derecho en la Universidad Carlos III de Madrid. Director del Grupo de Investigación sobre el Derecho y la Justicia (Gidyj). Director de Eunomía. Revista en Cultura de la Legalidad. Coordinador del Programa en Cultura de la Legalidad. Investigador Principal de la Red de Investigación española en Cultura de la Legalidad y Lucha contra la Corrupción. Entre sus recientes publicaciones destacan: «Derechos colectivos y Teoría del Derecho. Más ideología que teoría» en Eunomía. Revista en Cultura de la Legalidad, 17, (2019), pp. 100-115; (ed.), El legado de Dworkin a la filosofia del Derecho. Tomando en serio el imperio del erizo, Madrid, Centro de Estudios Políticos y Constitucionales, 2015 y (ed.), Aviones usados como bombas. Problemas politicos y constitucionales en la lucha contra el terrorismo, Catarata, Madrid, 2015.
} 
Palabras-clave: Justicia transicional, Memoria histórica, Democracia y tribunales internacionales, Marcos deliberativos.

\begin{abstract}
The Gelman case entails the conviction of Uruguay for violation of the rights to recognition of legal personality, to life, to personal integrity and to personal liberty; to the family, to the name, to the rights of children and to nationality, to the protection of the family, to judicial guarantees and judicial protection and because has failed to comply with the obligation to adapt its domestic law to the American Convention on Human Rights. Protected by the democratic legitimacy of the referendums that validated the Expiry Law, Uruguay has extended impunity for the crimes of the dictatorship by not executing the sentence. The author criticizes the validity of these exculpatory arguments of this unfulfilment based on various reasons.
\end{abstract}

Key-words: Transitional Justice, Historical Memory, Democracy and International Courts, Deliberative Frameworks.

\title{
Introducción
}

Las relaciones entre Estado de Derecho y democracia o entre derechos y regla de la mayoría constituyen un debate clásico al que sucesivos contextos nos remiten constantemente. Uno de ellos viene de la mano de la Corte Interamericana de Derechos Humanos (Corte IDH), que ha condenado las graves violaciones de derechos humanos como la tortura, desapariciones y crímenes de lesa humanidad cometidas por las dictaduras latinoamericanas durante la segunda mitad del siglo XX. En este escenario, la Corte IDH ha rechazado la aprobación de leyes contrarias a los estándares del Sistema Interamericano de Derechos Humanos y ha adoptado un relevante papel de defensa, promoción y protección de los derechos reconocidos en la Convención Americana sobre Derechos Humanos $(\mathrm{CADH})^{3}$. Esta labor le ha llevado a desarrollar progresivamente una jurisprudencia que es considerada como paradigmática (González, 2015) o, incluso, enarbolada como central en la construcción de un Ius Constitutionale Commune en América Latina (Von Bogdandy et al., 2017).

Sin embargo, su defensa de los derechos, su argumentación y su interpretación de la CADH han suscitado diversas confrontaciones jurídicas, políticas y académicas. Los casos relacionados con las leyes de amnistía, así como el control de convencionalidad, han generado algunas críticas centradas

\footnotetext{
${ }^{3}$ Véase Caso Barrios Altos Vs. Perú de 14 de marzo de 2001.
} 
en señalar que la Corte IDH, en el ejercicio de su función contenciosa, no estaría respetando las decisiones tomadas por las mayorías democráticas o los poderes democráticos de los Estados latinoamericanos, o que pretende arrogarse el papel de un tribunal activista y jerárquicamente superior a los ordenamientos nacionales. La sentencia del Caso Gelman (de 24 de febrero de 2011: Caso Gelman Vs. Uruguay) es un buen ejemplo pues, además de aludir a las reparaciones concretas, falla una serie de cláusulas extensivas al conjunto de los delitos de lesa humanidad y exige al Estado de Uruguay garantizar que la Ley de Caducidad ("núcleo duro de la impunidad", Buriano, 2011: 103), no dificulte las investigaciones y que los jueces y tribunales no puedan alegar prescripción, cosa juzgada, irretroactividad u otras causales que pretendan evitar un debido cumplimiento de la sentencia aun cuando dicha ley fue ratificada con un 56\% de los uruguayos en un referéndum realizado en 1989 y nuevamente en un plebiscito en 2009.

Nos encontramos ante un caso en el que la legitimidad de un tribunal internacional de derechos humanos parece entrar en colisión con el principio democrático de toma de decisiones por mayoría. Sin embargo, el debate es más complejo porque la reflexión debe considerar, primero, si puede contar con legitimidad democrática una consulta ciudadana local sobre amnistías -sea referéndum, sea plebiscito- $\mathrm{y}$, segundo, si esta legitimidad se encuentra o no condicionada por el contexto social, político y jurídico en el que las consultas se llevaron a cabo. El debate, además, no puede darse al margen del sinuoso camino transitado por la Suprema Corte de Justicia uruguaya que, a día de hoy, sigue sin atender el control de convencionalidad e imponiendo obstáculos para la identificación y procesamiento de los responsables de los crímenes cometidos durante el gobierno cívico militar.

Este debate sigue estando vigente, no sólo desde un punto de vista teorético, sino también práctico ya que la impunidad es una cuestión que a día de hoy "permanece abierta" (Castro, 2018: 26), como queda acreditado por el papel desempeñado por el Poder Judicial uruguayo, y porque todavía no se ha logrado "la verdad, la justicia y la reparación para las víctimas" del terrorismo de Estado ejercido durante el periodo 1973-1985 (Amnistía Internacional, 2018).

El presente texto se divide en cuatro partes. Una comprensión adecuada de los hechos requiere de un encuadre, aunque sea sucinto, del contexto histórico. Por ello, la primera parte describe el llamado "Caso Gelman" desde su inicio, en el marco de la dictadura militar, hasta la presentación de la demanda en la Corte IDH, ya en democracia. La segunda, se centra en el proceso de transición a la democracia poniendo énfasis en la Ley de Caducidad de la Pretensión Punitiva del Estado y sus consecuencias políticas, sociales y jurídicas. Esta contextualización pretende ofrecer elementos que coadyuven a la comprensión 
del fallo de la Corte IDH y evitar atender la discusión teórica sobre la legitimidad y la democracia en abstracto. La tercera parte analiza los impactos, institucionales y académicos, de la Sentencia de la Corte Interamericana de Derechos Humanos Caso Gelman Vs. Uruguay, de 24 de febrero de 2011. Finalmente, la cuarta se ocupa del análisis de la relevancia de la legitimidad democrática de la Ley de Caducidad y examina si la presunta deliberación democrática que le antecede es título suficiente para exigir la deferencia de la Corte IDH para con el legislador estatal.

\section{Juan Gelman y Macarena Gelman: cuarenta años esperando respuestas}

Hace poco más de cuarenta años, Uruguay se adentró en el camino de la represión, el miedo, la violencia y la impunidad, participando del oscuro periodo de los desaparecidos de las dictaduras del cono sur latinoamericano asociadas a la Operación Cóndor, que consistió en una coordinación represiva regional entre Argentina, Bolivia, Brasil, Chile, Paraguay y Uruguay en las décadas del 70 y del 80 y que es calificada como "una coordinación del terror, más allá de cualquier frontera, no solo geográfica sino también moral" (Lessa, 2016b: conferencia).

En 1976, Ma Claudia García Iruretagoyena y su pareja, Marcelo Gelman, desaparecieron en Argentina; después se supo que ella, embarazada de varios meses, fue trasladada en un vuelo clandestino a Montevideo dando a luz en el Hospital Militar a una niña. Marcelo fue localizado dentro de un tonel con cemento en un canal del Río de la Plata y a día de hoy Claudia sigue desaparecida. La niña fue entregada a un funcionario policial uruguayo de alto rango quien la registró como Macarena Tauriño. Aproximadamente 24 años después, Macarena recuperó su identidad y su historia tras haber sido hurtada, engañada y desaparecida.

La búsqueda de $\mathrm{M}^{\mathrm{a}}$. Claudia y su hijo/a empezó al poco de desaparecer. Las investigaciones privadas y los testimonios recabados por los familiares dieron la pista de su traslado a Uruguay. Su abuelo, el conocido poeta argentino Juan Gelman, hace pública en 1999-2000 una carta que envía al presidente Sanguinetti pidiendo que el Estado uruguayo cooperara para encontrar a su nieto/a. La respuesta de Sanguinetti fue que había hecho una "discreta averiguación" pero que "en territorio uruguayo no se han denunciado casos de pérdida de identidad de menores" (Sanguinetti, 1999).

Cerrada esta puerta, Gelman comienza una cruzada internacional y recibe el apoyo de conocidas figuras de la literatura e intelectuales de muchas partes del mundo; se inicia así una campaña epistolar que exige respuestas al 
presidente Sanguinetti en la que participan más de cien poetas, escritores y Premios Nobel como José Saramago, Dario Fo, Rigoberta Menchú y Gunther Grass, el único que obtuvo una respuesta ${ }^{4}$. Juan Gelman continuó con sus pesquisas ayudado por estas muestras de apoyo que irrumpieron fuertemente en el escenario público uruguayo.

Tan sólo unos meses después, cuando Jorge Battle era presidente, se reconoce oficialmente que la hija de $\mathrm{M}^{\mathrm{a}}$. Claudia García y Marcelo Gelman era la persona cuyos datos habían sido proporcionados al abuelo y que coincidían con los informes recolectados en la investigación paralela que este presidente había encomendado. El presidente Battle anuncia públicamente, tras las pruebas de ADN, que la nieta de Juan Gelman había sido identificada viva en Montevideo y éste se encuentra, en marzo del 2000, con su nieta que vivía con una familia de apropiadores.

Gelman inicia los trámites de una demanda penal denunciando la detención y desaparición forzada de su nuera y la sustracción de identidad de su nieta. Sin embargo, el presidente Battle dejó sin efecto la acción judicial y, en uso de sus prerrogativas, se negó a dar curso a las investigaciones, acogiéndose a la Ley de Caducidad de la Pretensión Punitiva del Estado (Ley 15.848). El 2 de diciembre de 2003 se archivó el caso; Gelman interpone una acción para que se declare inconstitucional dicho archivo, pero la Suprema Corte de Justicia (SCJ) rechaza la acción.

En 2005 cambia el gobierno y llega al poder Tabaré Vázquez del Frente Amplio, coalición de izquierda surgida en los preludios del autoritarismo. Comienzan a darse cambios en la forma de abordar el pasado reciente y aunque no se logra la eliminación de la Ley de Caducidad, se producen procesamientos relevantes y se tramita la reapertura de la investigación del caso de $\mathrm{M}^{\mathrm{a}}$. Claudia y de su hija. El nuevo mandatario exepciona el caso de $\mathrm{M}^{\mathrm{a}}$. Claudia de la Ley 15.848 y se reabre la investigación, pero el fiscal lo considera "cosa juzgada" y el Tribunal de Apelaciones revoca el dictamen impugnado y da por dirimida la controversia. La acción legal se archiva, nuevamente, en octubre de 2005.

La clausura del caso en las instancias uruguayas, junto con el inflexible silencio de militares, policías y civiles con información, complicidad o responsabilidad en los delitos, dio lugar a que Juan Gelman y su nieta, quien ya había adoptado el nombre de Macarena Gelman y tramitado su inscripción registral como hija legítima de Marcelo Gelman y $\mathrm{M}^{\mathrm{a}}$. Claudia García, impulsarán conjuntamente una querella en 2006 contra el Estado de Uruguay ante la Comisión Interamericana de Derechos Humanos (CIDH). En esta querella señalaban que, con base en la Ley Uruguaya de Caducidad, se bloqueaban las investigaciones sobre la desaparición de $\mathrm{M}^{\mathrm{a}}$. Claudia y

\footnotetext{
${ }^{4}$ En ella se negaba no solo de la desaparición en Uruguay de la nuera y nieto/a de Juan Gelman, sino incluso la participación de Uruguay en el Plan Cóndor. Véase (Parra, 2020).
}

Araucaria. Revista Iberoamericana de Filosofí, Política, Humanidades y Relaciones Internacionales, año $23, \mathrm{n}^{\circ} 46$. Primer cuatrimestre de 2021. Pp. 529-551. ISSN 1575-6823 e-ISSN 2340-2199 https://dx.doi.org/10.12795/araucaria.2021.i46.26 
se bloqueaba la persecución penal contra los responsables de la sustracción de identidad de Macarena. La CIDH recomendó al Estado de Uruguay que cumpliera con la Convención Americana de Derechos Humanos (CADH) que había suscrito en abril de 1985 y que investigara las causas y procesara a los responsables. En diciembre de 2009, la CIDH determinó que el Estado uruguayo no había dado cumplimiento satisfactorio a las recomendaciones que se le habían trasladado en agosto de 2008 y en enero de 2010 la CIDH trasladó a la Corte IDH el expediente con toda la información que había reunido.

El 24 de marzo de 2011, la Corte IDH falla la sentencia Gelman Vs. Uruguay. Antes de ver los detalles del fallo, conviene describir previamente las vicisitudes surgidas en torno a la Ley de Caducidad, a fin de tener más elementos de juicio a la hora de analizar la sentencia y sus consecuencias políticas y jurídicas.

\section{Contexto histórico y Ley de Caducidad de la Pretensión Punitiva del Estado}

En la segunda mitad de la década de los sesenta se inicia en Uruguay una reacción represiva contra la disidencia que, más tarde, llevó a vetar a los partidos de izquierda, a limitar -e incluso reprimir- derechos individuales, a torturar a un porcentaje significativo de la población y a otorgar cada vez más poder a los militares. Se abandonó así el presidencialismo de compromiso y se abrió las puertas a un presidencialismo "duro, autoritario y adversativo" (Lanzaro: 1998: 157).

En 1971 es elegido como Presidente de la República, el conservador Juan María Bordaberry quien endurece la política de su predecesor y hace suya -tras una fuerte presión militar- la doctrina de la seguridad nacional. Poco tiempo después de acceder al poder, disuelve las Cámaras y los consejos locales que habían sido democráticamente electos; más tarde, declara ilegales todas las asociaciones y organizaciones políticas; clausura la prensa; interviene la universidad y prohíbe las manifestaciones públicas; en suma, se cercenan las libertades y se encarcela y tortura masivamente, sembrándose así odio y desconfianza.

Este golpe de Estado dio lugar a una dictadura cívico militar que estuvo vigente hasta 1985. El fin de este gobierno autoritario no estuvo exento de complicaciones y entre las cuestiones más polémicas estuvo una negociación, confirmada en dos procesos de amnistía (sin mencionar dicho concepto), en la que las partes "se comprometían recíprocamente a la entrega del poder a cambio de impunidad y olvido" (Galain, 2014: 36). Ambos procesos, reflejados en dos leyes, fueron manejadas para fundamentar una "simetría de la culpa" (Dutrénit y Varela, 2010: 96) entre la guerrilla del Movimiento de Liberación Nacional 
mln-Tupamaros y las fuerzas armadas "en un intento por presentar falsamente el golpe de Estado como emanado de una de guerra civil a todas luces inexistente" (Buriano, 2011: 96). Al tiempo, una de las primeras decisiones fue aprobar, en abril de 1985, la adhesión a la Convención Americana sobre Derechos Humanos (Pacto de San José) y reconocer la competencia contenciosa de la Corte Interamericana de Derechos Humanos.

El primero de estos procesos fue la aprobación de la Ley de pacificación nacional (Ley $\mathrm{n}^{\circ}$. 15.737 de 8 de marzo de 1985), una semana después de que Sanguinetti asumiera la Presidencia. Esta Ley decreta la amnistía de todos los delitos políticos cometidos después del 1 de enero de 1962 (inicio de la guerrilla), quedando excluidos los que habían participado en la denominada guerra sucia. Los militares reaccionaron negativamente, consideraban justificada su actuación y, en consecuencia, incomprensible la posible libertad de los que eran considerados subversivos.

En un contexto de presión mediática y de mensajes en torno a la unidad nacional, aunado a la presión y a la hostilidad de las fuerzas armadas, junto con el riesgo de desacato que anunciaban los militares citados a declarar por parte de la justicia ordinaria, se promovió el segundo proceso de amnistía con la aprobación de la Ley de Caducidad de la Pretensión Punitiva del Estado (Ley n ${ }^{\circ}$. 15.848, de 22 de diciembre de 1986. En adelante Ley de Caducidad) ${ }^{5}$, el mismo día en que debían comparecer ante la justicia los primeros militares. Con esta Ley se puso fin a 38 casos con más de 400 acusaciones en contra de 180 personas que se habían iniciado judicialmente. Esta Ley, "con su farragosa denominación que escamotea bajo un recurso semántico su voluntad de amnistiar, la aprobó el Parlamento por las mayorías de los partidos Colorado y Nacional, con escasas y honrosas excepciones de personalidades y tendencias, así como la negativa unánime del conjunto de los legisladores del Frente Amplio y de la Unión Cívica” (Buriano, 2011b: 174).

Además de la presión de las fuerzas armadas, quienes estaban a favor de esta Ley esgrimían motivos estratégicos (políticos y sociales), tales como la estabilidad política, o juicios sobre la conveniencia de mirar hacia el futuro y superar el pasado y sobre la necesidad de perdonar para asegurar la paz social (Durán, 2014). Las acciones del poder ejecutivo en esos años fueron de obstrucción a "cualquier avance en el esclarecimiento del pasado y el ejercicio de la justicia, dado que su prioridad fue la consolidación de la democracia y

\footnotetext{
${ }^{5}$ La Ley 15.848 dispone que había caducado el ejercicio de la pretensión punitiva del Estado en relación a los delitos cometidos entre 1973 y el $1^{\circ}$ de marzo de 1985 por funcionarios militares y policías, equiparados y asimilados. Por su parte, el artículo $3^{\circ}$ establece que los jueces elevaran todas las denuncias al Poder Ejecutivo con el fin de que éste decidiera si estaban comprendidos bajo la Ley de Caducidad, a efectos de, si era el caso, ordenar que se archivaran. El artículo $4^{\circ}$ pone en manos del Poder Ejecutivo la investigación de las denuncias relacionadas con personas presumiblemente detenidas en operaciones militares o policiales y desaparecidas, así como de menores presuntamente secuestrados en condiciones similares.
} 
para ello el esclarecimiento del pasado era percibido como peligroso, dado que podía producir inestabilidad y nuevos enfrentamientos con las Fuerzas Armadas" (Lessa y Flores, 2016: 262).

Por su parte, el argumento esencial de los críticos de la Ley se centraba en la impunidad que generaba y propagaba su aprobación, amén de su oportunismo político y de posibles conflictos de inconstitucionalidad. En relación a esto último, la Corte Suprema de Justicia resolvió, "en una decisión judicial dividida y fundamentada con numerosos argumentos políticos", que la Ley de Caducidad era constitucional (Galain, 2016: 398). En cambio, organizaciones de derechos humanos, amplias capas de la opinión pública y el Frente Amplio se movilizaron y buscaron la forma de poder derogarla.

Se dirigieron esfuerzos para reunir firmas y celebrar un referéndum derogatorio de dicha Ley. Tras una dura campaña electoral de dos años, "boicoteada y desafiada a cada paso por las fuerzas gubernamentales e institucionales bajo el pretexto de detener una inminente crisis institucional" (Fried, 2016: 289), en la que partidos tradicionales defendieron "a capa y espada" la ley y donde campaba la amenaza constante de un probable pronunciamiento militar en caso de triunfar la derogación, el resultado del referéndum, celebrado el 16 de abril de 1989, fue favorable al mantenimiento de la ley con un 55.9\% de "votos amarillos" frente al $41.3 \%$ de "votos verdes".

Esta "especie de legitimación popular" (Fornasari, 2016:175) se explica, además de por el miedo a una nueva ruptura institucional y al retorno de los militares y la violencia, por otras razones como son "la "duplicidad" y las "zonas grises" en la población civil que aún no se han explorado en el caso uruguayo, en relación a la complejidad de los diversos grados de conservatismo, ambivalencia y complicidad civil "no voluntaria", siempre necesarios en la base de un régimen de facto tan totalitario como el uruguayo" (Fried, 2016: 290).

Si bien era complicado negarse a acatar la voluntad ciudadana, varias razones sustentaban esta negativa: "el argumento fundamental residía en que, más allá de que la ciudadanía hubiera decidido mantener la Ley de Caducidad en 1989, ésta era incompatible con la legislación internacional suscrita por el Estado uruguayo, a cuya norma debía someterse. Si no lo hacía por la vía legislativa o judicial, la Constitución de la República preveía este mecanismo supletorio" (Buriano, 2011b: 186) ${ }^{6}$.

\footnotetext{
${ }^{6}$ Una vez fracasada la iniciativa que buscó derogar la Ley de Caducidad a nivel nacional, una Organización No Gubernamental de Uruguay denominada IELSUR, junto con Human Rights Watch, iniciaron seis meses después una campaña en contra de esta ley de amnistía a nivel internacional. Ocho casos se presentaron ante la Comisión Interamericana de Derechos Humanos relacionados con la violación del derecho a la vida y del derecho a la integridad física cometidos durante la dictadura. En sus denuncias alegaban que la Ley de Caducidad violaba la Convención Americana sobre Derechos Humanos, ratificada por el Estado uruguayo en marzo de 1985.
} 
A pesar de la derrota que marcó el inicio de veinte años de absoluta impunidad, los defensores de la memoria del "espacio verde" siguieron su batalla contra la arbitrariedad y, aunque el silencio reinaba en las calles, mantuvieron en voz alta su discurso de que la transición se estaba dando mediante un proceso contencioso y no consensuado. Sin embargo, no solo fracasaron casi todos los intentos de denuncia, sino que, además, durante el gobierno de Lacalle, siguieron los operativos del Plan Cóndor (affaire Eugenio Berríos).

Entre este referéndum de 1989 y el plebiscito de 2009 salió a la luz pública la búsqueda de Juan Gelman de su nieta. En el año 2006, se funda la Coordinadora Nacional por la Nulidad, presidida por Eduardo Galeano, que buscaba derogar los primeros cuatro artículos de la Ley de Caducidad y para logar tal fin activan la segunda consulta popular. Días antes de la consulta, la Suprema Corte de Justicia de Uruguay declaró la inconstitucionalidad de la Ley de Caducidad en un caso concreto relativo al asesinato de una activista comunista en 1974, Nibia Salbasagaray. La Corte dictó, el 19 de octubre de 2009, una sentencia que establecía que la Ley de Caducidad violaba la separación de poderes; que en el momento de ser promulgada no había obtenido la mayoría requerida; y que violaba los compromisos en materia de derechos humanos que Uruguay había contraído, especialmente el derecho a la verdad y la justicia de las víctimas ${ }^{7}$. No obstante, esta decisión que ponía en tela de juicio la constitucionalidad de la Ley de Caducidad, sólo tenía significación para el caso concreto y no suponía la anulación de la misma ni tampoco era obligatoria para casos futuros, aunque sí dejaba en evidencia el drástico demarque con la decisión adoptada por dicha institución en 1988, cuando sostuvo la constitucionalidad de la ley ${ }^{8}$.

A pesar de la campaña y de la decisión de la Suprema Corte de Justicia, la consulta popular de 2009 no tuvo éxito pues tan sólo el 47.98\% de los votantes optó por su supresión. De acuerdo con Mallinder, el resultado de la votación se debe a varios factores. Primero, ya se habían dado pasos en la recuperación de la

7 Sentencia 365/2009 de 19 de octubre de la Corte Suprema de Uruguay (Caso Salbasagaray). Resulta llamativa la importante construcción doctrinal que sigue la Corte, siendo prolíficas las referencias académicas. Solo un ejemplo: "La "esfera de lo no decidible" (de Ferrajoli) es una expresión de un contenido significativo similar a la del "coto vedado" de Garzón Valdés, o a la del "territorio inviolable" de Norberto Bobbio". Considerando III.3) pfo. 7. Asimismo, la Corte se hace eco de la jurisprudencia de la Corte IDH, trayendo a colación además del citado Caso Barrios Altos (2001), al Caso Almonacid Arellano y otros y al Caso La Cantuna (SS. Corte IDH de 26 septiembre y 29 de diciembre de 2006, respectivamente).

8 De acuerdo con la Constitución Uruguaya, la Corte Suprema de Justicia puede declarar la inconstitucionalidad de una ley en casos específicos. En noviembre y diciembre de 2010 se pronunciaron otras dos sentencias de inconstitucionalidad y el 27 de octubre de 2011 se promulga la Ley 18.831, titulada Pretensión Punitiva del Estado: Restablecimiento para los delitos cometidos en aplicación del terrorismo de Estado hasta el $1^{\circ}$ de marzo de 1985, que cancela los efectos de los artículos 1, 2 y 3 de la Ley de Caducidad, en respuesta al fallo del Caso Gelman. La situación daría nuevamente un vuelco en febrero y marzo de 2013, cuando la Suprema Corte de Justicia declara inconstitucional la Ley 18.831.

Araucaria. Revista Iberoamericana de Filosofia, Politica, Humanidades y Relaciones Internacionales, año $23, \mathrm{n}^{\circ} 46$. Primer cuatrimestre de 2021. Pp. 529-551. ISSN 1575-6823 e-ISSN 2340-2199 https://dx.doi.org/10.12795/araucaria.2021.i46.26 
verdad y en el esclarecimiento de algunos responsables por lo que hubo quienes no consideraban urgente anular la Ley de Caducidad. Segundo, algunos sectores se oponían a una nueva consulta argumentando que la ciudadanía ya se había pronunciado sobre ello. Tercero, la discusión y el problema de la impunidad se centraron en argumentos legales, dejando al margen importantes cuestiones sociales y políticas. Cuarto, de acuerdo con el procedimiento, los votantes a favor de la nulidad de la amnistía debían incluir un sí en la papeleta, en tanto que los opositores no tenían que escribir nada (Mallinder 2016: 134). Además, el plebiscito pudo perder repercusión al desarrollarse junto a las elecciones parlamentarias y nacionales, en cuya campaña el Frente Amplio estuvo inmerso en una compleja coyuntura.

Lo anterior da cuenta de la "especificidad del caso uruguayo", el cual, como bien señalan Abraham y Mattei, se caracteriza no tanto por el hecho de que los uruguayos rechazaron el camino de la verdad y el de la justicia penal retributiva sino porque, al contrario de muchos otros casos, respaldaron en las urnas la amnistía para los violadores de derechos humanos en dos consultas populares promovidas paradójicamente para derogar la Ley de Caducidad, "en un país en donde el imaginario colectivo coloca al voto como la esencia de la identidad nacional y la forma uruguaya de dirimir los conflictos" (Sempol, 2016:57). Y esta especificidad, desplegada en un escenario singular y complejo, también se debe al hecho de que el Parlamento uruguayo votó en 2011 una Ley que suspendió los efectos de la Ley de Caducidad (Abraham y Mattei, 2012). La pregunta que se presenta es: ¿sobre qué argumentos de legitimidad democrática se ha sustentado la decisión del Parlamento de suspender una ley refrendada dos veces en consulta popular?

Con la síntesis anterior he querido mostrar que la Ley de Caducidad es un mecanismo "sui generis del proceso uruguayo de transición que se presenta como la viva prueba del sometimiento de la justicia a la oportunidad política" (Galain, 2016: 398). La interpretación jurídica de la misma ley ha cambiado de forma drástica dependiendo del momento político en el que la Suprema Corte de Justicia es consultada. Esta ley, mecanismo político de la transición, ha estado permanentemente presente en la búsqueda de justicia, una "justicia" emanada de criterios jurídicos variables o de consultas populares; una ley que confiere al Poder Ejecutivo la facultad de decidir sobre cuestiones concernientes al Poder Judicial, relacionadas con la persecución de los crímenes cometidos por el régimen autoritario. Además, la Ley de Caducidad sigue impidiendo que muchos familiares de las víctimas puedan ser oídos por un juez y que se capturen, procesen y condenen a los responsables de múltiples delitos. En suma, en el caso uruguayo las decisiones relacionadas con la búsqueda de justicia, tras el periodo de la dictadura, han estado continuamente influidas y maniatadas por las coyunturas políticas y la correlación de fuerzas en el poder. 


\section{La sentencia Caso Gelman Vs. Uruguay de la Corte Interamericana de Derechos Humanos}

El 24 de febrero de 2011 la Corte IDH dictó el primer fallo contra Uruguay, conocido como el "Caso Gelman", que tuvo fuertes repercusiones y sigue generando intensos debates. En la sentencia, la Corte IDH declara por unanimidad responsable al Estado uruguayo por la desaparición forzada de $\mathrm{M}^{\mathrm{a}}$. Claudia García Iruretagoyena; por la sustracción, supresión y sustitución de identidad de su hija; por haber violado el derecho a la integridad personal y a la protección de la familia de Juan Gelman; por la violación de derechos y garantías judiciales; por la falta de investigación efectiva de los hechos; por incumplir la obligación de adecuar su derecho interno a la CADH como consecuencia de la interpretación y aplicación de la Ley de Caducidad. Asimismo, exige, por un lado, que se asegure la eficacia de la investigación en un plazo razonable y se garantice que la Ley de Caducidad no sea un obstáculo; por el otro, que realice un acto público de reconocimiento de responsabilidad internacional; $\mathrm{y}$, finalmente, que se implemente en un plazo razonable un programa permanente de derechos humanos dirigido a los agentes del Ministerio Público y a los jueces del Poder Judicial y se paguen las indemnizaciones correspondientes.

En relación a las graves violaciones de derechos humanos que tuvieron lugar en Uruguay y las implicaciones sobre las mismas de la Ley de Caducidad, el Tribunal dispone que el Estado debe asegurar que no sea aplicada ninguna norma que suponga prescripción, irretroactividad de la ley penal, cosa juzgada, non bis in ídem, o cualquier excluyente análogo de responsabilidad. Reafirma su jurisprudencia y advierte que cuando un Estado es parte de un tratado internacional, en clara alusión a la $\mathrm{CADH}$, todos sus órganos y sus jueces están sometidos a dicho tratado, lo cual les obliga "ex oficio" a un control de convencionalidad teniendo presente que la intérprete última de la CADH es la Corte IDH.

En relación a las amnistías, el Tribunal Interamericano señala su incompatibilidad con la CADH en casos de violaciones graves a los derechos humanos, tal y como ya se había pronunciado en el caso Barrios Altos Vs. Perú. Asimismo, dispone que la sentencia constituye per se una forma de reparación.

\subsection{Impacto y reacciones de los poderes legislativo y ejecutivo}

Entre las notas positivas de la condena, podemos mencionar, por un lado, el triunfo histórico de su mera existencia (Fried, 2016); por otro, su contribución a la consolidación de los derechos humanos en la región (Escandar, 2015) y a construir una institucionalidad más respetuosa con su protección (Dutrénit, 2012); finalmente, su exigencia al Estado para hacer pública su responsabilidad 
internacional y pedir disculpas a las víctimas contribuyendo con ello a la construcción de la memoria y al esclarecimiento de la verdad.

Sin embargo, la impunidad sigue presente y las respuestas oficiales del Estado de Uruguay a la sentencia de la Corte IDH "han sido contradictorias, ambivalentes, y (...) con contramarchas significativas" (Fried, 2016: 305). Para Uruguay, el fallo involucró a los tres poderes del Estado y pasó a ocupar un espacio central en la sociedad y en el debate público, donde se han desencadenado luchas intestinas.

En el terreno del poder legislativo, el fallo de la Corte IDH motivó la presentación de varias propuestas legislativas para anular la Ley de Caducidad. Sin embargo, las iniciativas no encontraron el apoyo suficiente en la Cámara Baja9 .

A finales de junio de 2011, el presidente Mujica firmó una resolución ( $n^{\circ} 322 / 2011$ ) que revocaba todos los actos administrativos de los antiguos presidentes que aplicaban el artículo $3^{\circ}$ de la Ley de Caducidad por el que se impedían las investigaciones de graves violaciones de derechos humanos. Esta resolución especificaba que se contemplaban las conclusiones de la sentencia de la Corte IDH y dio causa a la reapertura de 88 casos que la Ley 15.848 había suspendido. Sin embargo, no se anulaba la amnistía y muchos defensores de derechos humanos consideraban que el decreto era insuficiente y que era necesaria la derogación de la Ley de Caducidad.

Grupos organizados y legisladores del Frente Amplio siguieron dando la batalla para neutralizar la amnistía y, el 25 de octubre de 2011, el Senado, con 16 votos a favor y 15 en contra, y la Cámara de Representantes -tras un duro debate- con 50 votos a favor y 40 en contra aprobaron la anulación de la amnistía. E1 27 de octubre fue promulgada la Ley no ${ }^{\circ} .18 .831$ titulada Pretensión Punitiva del Estado: Restablecimiento para los delitos cometidos en aplicación del terrorismo de Estado hasta el $1^{\circ}$ de marzo de 1985, cuyo primer artículo revocaba la Ley de Caducidad y restablecía la pretensión punitiva del Estado hasta el $1^{\circ}$ de marzo de 1985 . Esta nueva ley convierte en crímenes de lesa humanidad los cometidos hasta la fecha mencionada de conformidad con los tratados internacionales firmados por la República del Uruguay.

No hubo un apoyo público generalizado ya que parte de la población pensaba que esta decisión quebrantaba lo expresado en la consulta popular (Roniger, 2011: 721-722) y/o que "la nulidad de la amnistía no es en sí misma suficiente para acabar con la impunidad por crímenes del pasado" (Mallinder, 2016: 140).

\footnotetext{
${ }^{9}$ Las presiones internas e internacionales fueron muy intensas y cuando una propuesta para derogar la Ley de Caducidad volvió al parlamento para su voto final, en medio de una sociedad civil notablemente polarizada, el presidente Mujica cambia su posición y hace un llamado a no revertir los resultados de la consulta popular (Roninger, 2011) advirtiendo a su bancada de los costos políticos que tendría para el Frente Amplio (Fried, 2016).
}

Araucaria. Revista Iberoamericana de Filosofia, Politica, Humanidades y Relaciones Internacionales, año $23, \mathrm{n}^{\circ} 46$. Primer cuatrimestre de 2021. Pp. 529-551. ISSN 1575-6823 e-ISSN 2340-2199 https://dx.doi.org/10.12795/araucaria.2021.i46.26 
Por su parte, el poder ejecutivo organizó el 21 de marzo de 2012, en la Asamblea General, el "acto público de reconocimiento internacional por los hechos" exigido en el fallo. Encabezado por el propio presidente José Mujica, asisten la familia Gelman, los ministros, los legisladores, los jueces de la SCJ, los miembros de la Secretaría de Seguimiento de la Comisión para la Paz, los tres jefes de las Fueras Armadas y el jefe del Estado Mayor de la Defensa, un juez uruguayo de la Corte IDH, representantes políticos, el rector de la Universidad de la República y miembros de organizaciones de derechos humanos. Este acto, transmitido por radio y televisión, "constituyó un verdadero parteaguas en la historia reciente del Uruguay" (Dutrénit, 2012: 95).

\subsection{Impacto y reacciones del poder judicial}

En la esfera judicial la reacción es más compleja. El 12 de febrero de 2013 la Suprema Corte de Justicia de Uruguay da a conocer una sentencia en la que declara inconstitucionales -y en consecuencia inaplicables al caso- los artículos 2 y 3 de la Ley $18.831^{10}$. Este fallo vuelve a recuperar el debate en torno al principio de legalidad penal y, especialmente, lo relacionado con la irretroactividad de la ley penal ya que, de acuerdo con la posición mayoritaria de la SCJ, las causas abiertas en las que no hay militares procesados por delitos cometidos durante la dictadura, deberían ser archivadas y que los delitos cometidos en la época de la dictadura no son de lesa humanidad, sino delitos comunes y, en consecuencia, ya prescribieron.

El debate en torno a la prescriptibilidad y la imprescriptibilidad de la Ley de Caducidad sigue estando presente ${ }^{11}$. Al respecto, la SCJ ha dictado decisiones contradictorias y aleatorias que dependen de mayorías circunstanciales, aunque en sus decisiones erráticas domina la tendencia a admitir la prescripción (Castro 2018). Este respaldo a la tesis de la prescripción, que implica la afirmación de la inconstitucionalidad de la Ley 18.831 que declara imprescriptibles los delitos de lesa humanidad, marca su discrepancia con dos tesis fuertes de la Corte IDH: la jurisprudencia interpretativa como precedente vinculante y la exigencia de control de convencionalidad (Castro 2018: 12).

Sin duda, una de las cuestiones más espinosas de la sentencia de la Corte IDH es el hecho de que la SCJ planteara que

\footnotetext{
${ }^{10}$ Estos artículos señalan: "Artículo $2^{\circ}$.- No se computará plazo alguno procesal, de prescripción o de caducidad, en el periodo comprendido entre el 22 de diciembre de 1986 y la vigencia de esta ley, para los delitos a que refiere el artículo $1^{\circ}$ de esta ley. Artículo $3^{\circ}$.- Declárese que, los delitos a que refieren los artículos anteriores, son crímenes de lesa humanidad de conformidad con los tratados internacionales de los que la República es parte».

11 Recientes sentencias dan cuenta de ello: SCJ 280/2017 y 1925/2017. En ellas se decreta nuevamente la prescripción de los crímenes de lesa humanidad cometidos por el Estado durante el periodo cívico-militar.
}

Araucaria. Revista Iberoamericana de Filosofia, Política, Humanidades y Relaciones Internacionales, año $23, \mathrm{n}^{\circ} 46$. Primer cuatrimestre de 2021. Pp. 529-551. ISSN 1575-6823 e-ISSN 2340-2199 https://dx.doi.org/10.12795/araucaria.2021.i46.26 
(...) si bien está fuera de toda discusión que la Corte IDH es la intérprete última de la Convención Americana de Derechos Humanos (...) tampoco puede desconocerse que la intérprete última de la Constitución de la República Oriental del Uruguay es la Suprema Corte de Justicia (Suprema Corte de Justicia, 2011: 21).

Estas palabras dan cuenta del distinto tipo de parecer que hay entre la SCJ y la Corte IDH, al margen de que el incumplimiento de la sentencia de la Corte IDH acarrea responsabilidad internacional del Estado.

Conviene recordar también que una semana antes de dictar esta sentencia, la SCJ traslada a la magistrada Mariana Mota, del Juzgado de Primera Instancia en lo Penal a un juzgado civil. La jueza investigaba más de 50 denuncias por violaciones a los derechos humanos relacionadas con la dictadura militar y había condenado en el 2010 al ex presidente Juan María Bordaberry por delitos de atentado contra la Constitución, desaparición forzada de personas y homicidio político. Su traslado fue interpretado por parte de la opinión pública con recelos y generó múltiples manifestaciones, nacionales e internacionales. Esta maniobra "sigue un largo patrón de previas obstaculizaciones y penalizaciones en forma de traslados a jueces y fiscales que se habían atrevido a avanzar" en causas similares (Fried, 2016: 309) y "pone sobre el tapete (...) la disposición efectiva de elaborar el pasado" (Engelhart, 2016: 44).

\section{Reflexiones sobre la legitimidad de la Sentencia del Caso Gelman}

El Caso Gelman pertenece a la lista de sentencias de la Corte IDH que han dictaminado el carácter anticonvencional de las diversas leyes de amnistía que han sido dictadas en transiciones de regímenes dictatoriales hacia sistemas democráticos ${ }^{12}$. El grado de legitimidad democrática que disfrutan estas leyes de amnistía no es uniforme y abre un abanico que va desde la nula legitimidad democrática de las leyes de autoamnistía dictadas por los órganos de la propia dictadura, hasta el refrendo popular directo que se sustanció en Uruguay con el referéndum y plebiscito, tantas veces citados, de las leyes adoptadas por legislaturas democráticas.

Este hecho perfila al Caso Gelman como una buena oportunidad para recrear el largo debate sobre el déficit democrático del que adolecen aquellos tribunales titulares de la competencia de enmendar las decisiones adoptadas por el legislador democrático y, más allá, por el pueblo directamente, mediante

\footnotetext{
12 Resulta especialmente interesante el apartado D. Incompatibilidad de las amnistías relativas a graves violaciones de derechos humanos con el Derecho Internacional del capítulo VIII de la Sentencia de 24 de noviembre de 2010, Caso Gomes Lund y Otros ("Guerrilha do Araguaia") vs. Brasil porque la propia Corte IDH elabora una completa relación de los casos sustanciados por ella, así como por la Comisión IDH y se extiende en un estudio comparado fuera del Continente.
} 
la expresión de su voluntad en procesos referendarios. De una forma más específica, el Caso Gelman recrea la cuestión no en el contexto interno del Estado, sino en la relación entre tribunales internacionales de protección de los derechos humanos y procesos democráticos locales.

Entre la amplia literatura que se ha ocupado de esta cuestión ${ }^{13}$, quisiera destacar aquí a Roberto Gargarella y su defensa del constitucionalismo dialógico (entre muchos, 2007 y 2014). En una visión favorable a la defensa de la democracia fuerte, Gargarella ha sostenido consistentemente las fórmulas de deferencia en favor del principio democrático y del reconocimiento de la legitimidad de la tarea legislativa por parte de los tribunales de última instancia, abundando en fórmulas y doctrinas colaborativas (2017). Asimismo, resultan especialmente útiles aquí los trabajos que ha dedicado a la cuestión en la perspectiva de los tribunales internacionales de protección de derechos humanos (2019) y, específicamente, al Caso Gelman (2013, 2015 y 2016).

Las críticas que sostiene Gargarella sobre la actuación de la Corte IDH en este caso pueden sintetizarse en tres ideas que, siguiendo sus propios términos, son: el problema de la gradación democrática; el problema del desacuerdo; y, finalmente, el problema de la diversidad del reproche estatal (2013: 1-2). El primero remite a la toma en consideración de la relevancia del grado de legitimidad democrática que tienen las leyes de amnistía, sosteniendo que la intensidad del carácter democrático del proceso legislativo de su adopción resulta relevante para su aceptabilidad. El segundo se refiere a la cuestión del pluralismo y de la irreductibilidad de los desacuerdos profundos y razonables, cuestión en línea de lo sostenido por los procedimentalistas (por todos Waldron, 1999a y 1999b), y aboga por superar lo que presenta como una dicotomía excluyente entre democracia y derechos humanos, incluyendo la crítica a la derivada adicional relativa a sostener la proclividad del principio de las mayorías (populares) a adoptar resoluciones irracionales frente a la racionalidad de las judiciales (institucionales). El tercero alude a la incorrección de la interpretación de la Corte IDH del art. 1 de la Convención, relativa a la univocidad de comprender "el deber (de los Estados parte) de respetar los derechos y libertades reconocidos en ella y a garantizar su libre y pleno ejercicio a toda persona que esté sujeta a su jurisdicción" como la adscripción de "deberes de 'prevenir', 'investigar', 'sancionar', restablecer y 'reparar' 'daños producidos por la violación de los derechos humanos'" $(2013,13)$. En esta interpretación, Gargarella suscita dos problemáticas relativas, respectivamente, a la teoría de la democracia y a la teoría del castigo $(2013,14)$. Esta última dimensión no va a ser examinada aquí porque, por un lado, creo que resulta colateral a la cuestión fundamental planteada por la sentencia; por otro, la intensidad del castigo y su tratamiento

13 Entre los trabajos recientes sobre la materia, resultan especialmente recomendables las perspectivas generales ofrecidas por Melero, 2020; Roa, 2019; Moreira, 2109 y Gaviria, 2017.

Araucaria. Revista Iberoamericana de Filosofí, Política, Humanidades y Relaciones Internacionales, año $23, \mathrm{n}^{\circ} 46$. Primer cuatrimestre de 2021. Pp. 529-551. ISSN 1575-6823 e-ISSN 2340-2199 https://dx.doi.org/10.12795/araucaria.2021.i46.26 
penitenciario no son abordados en ella y, finalmente, habría una multiplicidad de dimensiones de lo que en alguna ocasión he llamado "derecho ciudadano a la memoria histórica" (Sauca, 2008 y 2011) y que, efectivamente, desbordan el contenido de esta resolución de la Corte de San José y, por demás, alimentarían las críticas a su carácter limitado y a su insuficiencia.

De esta manera, creo que puede sintetizarse que los dos primeros problemas, así como el primer inciso del tercero, son el fundamento de los reparos de Gargarella a la falta de deferencia debida de la Corte IDH a la voluntad democrática del pueblo uruguayo. Así, desde las premisas teóricas del constitucionalismo dialógico o deliberativo, la Corte habría incurrido en una posición de extralimitación de sus poderes atentando injustificadamente al respeto debido del principio democrático. No comparto este balance y creo que pueden sintetizarse las razones de esta discrepancia en tres consideraciones, una empírica y dos teóricas.

En primer lugar, compartiendo con el autor la razonable diferencia que existe en la gradualidad de la legitimidad democrática de las distintas leyes de amnistía, hay una cuestión fáctica que no puede presuponerse. Gargarella sostiene que, del hecho de la aprobación de la Ley de Caducidad por una legislatura democrática, de su ratificación en referéndum y en un plebiscito se sigue la legitimidad democrática de dicha ley. Es indudable que el incremento de participación ciudadana alienta la verosimilitud de esta conclusión, pero no resuelve la evaluación de las condiciones que sustanciarían la legitimidad de la decisión. Los análisis empíricos, y este lo es, requieren un análisis de las circunstancias específicas que caracterizan al proceso político correspondiente y que no debieran ser presupuestas sobre la base de presunciones de carácter formal. Así, por un lado, la doctrina de la deferencia distingue la sumisión del respeto y justifica por ello la competencia de los tribunales para determinar las condiciones de representatividad, afectación y proporcionalidad de las condiciones específicas del proceso democrático que se haya seguido (Lazarus y Simonsen, 2015: 392-398; Hunt, 2003: 350-351). Por otro, la realidad es mucho más compleja que observaciones puramente formales sobre el proceso electoral. Traigo a colación el caso español como ejemplo de esta complejidad. La ley de amnistía de 1977 es dictada por un parlamento democrático, pero solo es la última fase de una serie de amnistías e indultos dictadas por parlamentos autocráticos $^{14} \mathrm{y}$, por demás, son el resultado de intensas movilizaciones de fuerzas políticas contrarias a la dictadura. De esta manera, de facto, nos encontraríamos ante la paradoja de una amnistía de los agentes de la dictadura

${ }^{14}$ La Ley de Amnistía 46/1977, de 15 de octubre se dictó por las Cortes electas el 15 de junio anterior y culminaba el proceso iniciado por el indulto dictado el 25 de noviembre de 1975 con ocasión del acceso al trono de Juan Carlos I y al Real Decreto Ley 10/1976, de 30 de julio, sobre Amnistía que se completó con Real Decreto Ley 19/1977, de 14 de marzo, mediante el cual el gobierno habilitó la fórmula de indultos con penas de extrañamiento que, finalmente, no fueron eficaces. 
resultado de una larga movilización de las fuerzas democráticas y opositoras al régimen (Aguilar, 1997 y 2012). En definitiva, una aproximación puramente formal (porcentaje de participación) al proceso legislativo, como la predicada en el caso uruguayo, está lejos de poder concluir que, en términos categóricos, goce de una legitimidad democrática que indebidamente desoyó la Corte. Cuando ésta señala en la sentencia que "la Ley de Caducidad haya sido aprobada en un régimen democrático y aún ratificada o respaldada por la ciudadanía en dos ocasiones no le concede, automáticamente ni por sí sola, legitimidad ante el Derecho Internacional" (considerando 239) creo que, razonablemente, está aludiendo a esta dimensión. No se puede presuponer que del mero hecho de una mayor participación se siga necesariamente una legitimidad democrática suficiente. Así, el carácter democrático no se presupone, sino que debe ser la conclusión de un estudio específico de las peculiaridades del proceso en concreto. A la vista de los resultados de dicha participación y de la reluctancia de la problemática creo que estamos lejos de ese consenso.

En segundo lugar, creo que la argumentación de Gargarella, de una manera transversal a los tres problemas que imputa a la Sentencia, presupone un marco de decisión unívoco y este presupuesto es discutible. Pareciera que identifica el marco de deliberación democrática con el relevante para la determinación de la composición del órgano competente para la producción de la norma en cuestión: paradigmáticamente el Estado $(2013,6)$. Así, el marco de relevancia para la determinación del proceso democrático de la Ley de Caducidad es el proceso democrático en las instituciones uruguayas. Gargarella niega explícitamente que mantenga una tesis nacionalista de reafirmación soberanista y creo que tampoco sostendría la superioridad dialógica del proceso político estatal frente a otros ámbitos de deliberación. Sin embargo, parece orillar la multiplicidad de niveles deliberativos democráticos y la interacción entre ellos ${ }^{15}$. El marco estatal no es el único marco en el proceso de toma de decisiones y resultan operativas varias esferas de ejercicio de la soberanía. Los niveles subestatales de ejercicio de la soberanía, vinculados a estructuras de descentralización o de devolución, o la diversificación del dónde vota el ciudadano (Bobbio, 1986: 21) serían ejemplos paradigmáticos; así como todo el universo del proceso democrático vinculado a la protección de las minorías mediante fórmulas de derechos especiales de representación, diversificación de los demoi y, de últimas, el reconocimiento de la inclusión en el derecho de voto de la potestad de delimitar el marco del voto.

Por otra parte, e igualmente relevante en el caso, existen espacios para la deliberación democrática que trascienden el contexto estatal y adquieren una relevancia superior a la del marco decisional específico de creación de la norma.

${ }^{15}$ Para un examen de la modulación del principio de subsidiariedad véase, entre varios trabajos del autor, Føllesdal, 2016.

Araucaria. Revista Iberoamericana de Filosofia, Política, Humanidades y Relaciones Internacionales, año $23, \mathrm{n}^{\circ} 46$. Primer cuatrimestre de 2021. Pp. 529-551. ISSN 1575-6823 e-ISSN 2340-2199 https://dx.doi.org/10.12795/araucaria.2021.i46.26 
No creo que sea exagerado sostener que hay un marco regional de deliberación política que se corresponde con el espacio cultural y político que denominamos Latinoamérica y que, a estos efectos, puede referir a la extensión del sistema interamericano. Las deliberaciones relativas a cuestiones trascendentales como el estatuto de la condena de los crímenes masivos o de lesa humanidad no son exclusivamente relevantes en el marco deliberativo estatal, sino que corresponde a un auditorio más amplio que no debe quedar constreñido por el argumento de la decisión estatal, por muy legitimada democráticamente que, en su caso, pudiera llegar a estarlo. No estoy abogando por un universalista humani nihil a me alienum puto, sino por la visión más moderada de que quod omnes tangit ab omnibus approbetur, y todos los afectados son la comunidad interamericana de derechos. En definitiva, las críticas a la Corte IDH no debieran recaer en la falta de toma en consideración de la decisión democrática local que sostiene, en opinión de Gargarella, la legitimación de la Ley de Caducidad, sino en las insuficiencias de una deliberación abierta en el proceso correspondiente en el nivel interamericano. Dichas insuficiencias incluirían, al menos, la marginación de la actividad de la Comisión IDH y los avances, por parte de la Corte IDH, en los procedimientos, medidas y prácticas de participación, audiencia pública, consulta y transparencia deliberativa susceptibles de reforzar la deliberación pública de sus decisiones, amén de su actividad consultiva.

En tercer lugar, la formulación en términos disyuntivos del deber de deferencia de la Corte respecto de las autoridades uruguayas que defiende Gargarella, diluyen un elemento sustancial de las aproximaciones dialógicas entre instituciones como es la dimensión procesual del diálogo y el carácter permanente del mismo. En estos parámetros de justificación de la deferencia en favor del principio democrático, constituye un lugar pacífico la comprensión de la colaboración institucional como una tarea permanente en la que, en alguna medida, se diluye la doctrina de la última palabra. La deferencia con el legislador modera la doctrina del poder decisional último en favor del tribunal supremo o constitucional de turno, pero no implica la reversión de la situación afirmando la superioridad o el carácter definitivo de la voluntad democrática, sino que convoca a la interlocución institucional y esta tiene carácter permanente (Iglesias, 2019; Brems, 2009). Desde esta perspectiva, cuando focalizamos la cuestión en la Corte IDH y su especial posición de interlocución con plurales legisladores, la defensa de este proceso colaborativo no se circunscribe a la interacción puntual entre un Estado miembro de la Convención y la propia Corte con ocasión de un contencioso, sino a un proceso deliberativo que acontece entre esta y las sucesivas instituciones legislativas estatales cuya actividad es, en su caso, objeto de estudio. En este proceso de interlocución con complejidad de intervinientes, los exámenes de deferencia, las cláusulas notwithstanding, reenvío, juicios de incompatibilidad y de discrecionalidad, las ponderaciones 
al caso, etc. revisten una continuidad más cercana a la figura dworkiniana del derecho como literatura que al de un juicio de abstención específico por razones procedimentales. Creo que no estaría desencaminado al sostener, como parece hacer el propio Gargarella (2019: 16-17), que los estándares normativos en el Proceso de Paz colombiano son muy superiores a los seguidos por los uruguayos en la Ley de Caducidad y que ello trae causa, precisamente, del proceso de interlocución que encuentra como más claros antecedentes el citado Caso Gomes Lund y Otros y el Caso Gelman.

En conclusión, ni está descontado que la existencia de un proceso democrático en Uruguay legitime, por su mera existencia, democráticamente la Ley de Caducidad; ni el marco estatal es adecuado para el desarrollo de estos procesos deliberativos de carácter democrático ni, finalmente, la deferencia puede interpretarse como sumisión singular sino como una interacción institucional compleja y permanente. En definitiva, las insuficiencias de la acción de la Corte IDH en el Caso Gelman estarían más cerca de la necesidad de aproximar su dinámica institucional a fórmulas deliberativas más abiertas que a la de someterse a la deferencia singular de una controvertida decisión democrática local atentatoria de los derechos en juego. 


\section{Bibliografía:}

Abraham, Nicolás y Mattei, Eugenia, "Nuevo comienzo democrático en Uruguay: la Ley de Caducidad en querella", African Yearbook of Rhetoric, 3(1) (2012), pp. 95-106.

Aguilar Fernández, Paloma, "The Spanish Amnesty Law of 1977 in comparative perspective: from a law for democracy to a law for impunity" en Francesca Lessa y Leigh A. Payne (coords.), Amnesty in the age of human rights accountability: comparative and international perspectives, Cambridge, Cambridge University Press, 2012, pp. 315-335.

Aguilar Fernández, Paloma, "La amnesia y la memoria: las movilizaciones por la amnistía en la transición a la democracia" en Manuel Pérez Ledesma y Rafael Cruz Martínez (coord.), Cultura y movilización en la España contemporánea, Madrid, Alianza Universidad, 1997, pp. 327-357.

Amnistía Internacional, Uruguay: Progresos constantes, deudas persistentes, 2018. En línea: ttps://www.amnesty.org/download/Documents/ AMR5288412018SPANISH.PDF

Bobbio, Norberto, El futuro de la democracia, México, Fondo de Cultura Económica, 1986.

Bogdandy, Armin von, Mariela Morales Antoniazzi y Eduardo Ferrer MacGregor, (coords.) Ius Constitutionale Commune en América Latina, México, Instituto de Estudios Constitucionales de Querétaro y Max Planck Institute for Comparative Public Law and International Law, 2017.

Brems, Eva, "Human Rights: Minimum and Maximum Perspectives", Human Rights Law Review, 9(3) (2009), pp. 349-372.

Buriano, Ana, "Derechos, trauma social y restitución. Sincronía y unicidad: el caso de Uruguay", Andamios. Revista de investigación social, 9(18) (2011) pp. 89-116.

Buriano, Ana, "Ley de Caducidad en Uruguay y esencia ético política de la izquierda", en Perfiles Latinoamericanos, México, FLACSO, 38 (2011b), pp. 173-203.

Castro, Alicia, "Derechos humanos y delitos de lesa humanidad. Un análisis de la jurisprudencia de la Suprema Corte de Justicia sobre imprescriptibilidad de los delitos de la dictadura" Revista de Derecho Público, 27 (2018), pp. 7-34.

Durán, Augusto, "La jurisprudencia de la Corte Interamericana de Derechos Humanos en la perspectiva del Derecho administrativo: especial referencia al caso Gelman Vs. Uruguay" Revista de Investigaçoes Constitucionals (Curitiba), 1(2) (2014), pp. 103-130. 
Dutrénit, Silvia, "Sentencias de la Corte Interamericana de Derechos Humanos y reacciones estatales. México y Uruguay ante los delitos del pasado", América Latina Hoy, 61, (2012), pp. 79-99.

Engelhart, Marc, "Objetivos de la justicia de transición”, en Pablo Galain (ed.), ¿Justicia de Transición? Mecanismos políticos y jurídicos para la elaboración del pasado, Valencia, Tirant lo Blanch, 2016.

Farrajoli, Luigi, "Por una teoría de los derechos fundamentales", en Luis González y Julieta Morales (coords.), Derechos humanos. Actualidad y desafíos, México, Fontamara, 2012.

Føllesdal, Andreas, "Subsidiarity and International Human-Rights Courts: Respecting Self-Governance and Protecting Human Rights - Or Neither?", Law and Contemporary Problems, 79 (2016), pp. 147-163.

Fornasari, Gabriele, "Dictadores al banquillo. El "caso Bordaberry" como piedra miliar de la justicia de transición en Uruguay", en Pablo Galain (ed.), ¿Justicia de Transición? Mecanismos políticos y jurídicos para la elaboración del pasado, Valencia, Tirant lo Blanch, 2016.

Fried, Gabriela, "Caducidad, oblivión, y la memoria social del terrorismo de Estado en el Uruguay de transición. Las "brechas" a la impunidad" en Pablo Galain Palermo (ed.), ¿Justicia de Transición? Mecanismos políticos y jurídicos para la elaboración del pasado, Valencia, Tirant lo Blanch, 2016.

Galain, Pablo, (2014), "El proceso de justicia transicional en Uruguay" Verba Iuris, 32 (2014) pp. 33-44.

Galain, Pablo, (ed.) ¿Justicia de Transición? Mecanismos políticos y jurídicos para la elaboración del pasado, Valencia, Tirant lo Blanch, 2016.

Gargarella, Roberto, "Un papel renovado para la Corte Suprema. Democracia e interpretación judicial de la Constitución”, en Guillermo I. Ortiz (pres.) Tribunales Internacionales y consolidación de la democracia, México, Suprema Corte de Justicia de la Nación, 2007.

Gargarella, Roberto, "Sin lugar para la soberanía popular. Democracia, derechos y castigo en el caso Gelman”, SELA Papers, 125 (2013) pp. 1-22.

Gargarella, Roberto, "“We the People' outside of the Constitution. The Dialogic Model of Constitutionalism and the System of Checks and Balances", Current Legal Problems, 61(1) (2014) pp. 1-47.

Gargarella, Roberto, "La democracia frente a los crímenes masivos: una reflexión a la luz del Caso Gelman", Revista Latinoamericana de Derecho Internacional, 24 (2015) pp. 1-15.

Gargarella, Roberto, "Justicia penal internacional y deliberación democrática. El caso Gelman”, en Pablo Santolaya e Isabel Wences (eds.), La América de los Derechos, Madrid, Centro de Estudios Políticos y Constitucionales, 2016. 
Gargarella, Roberto, “Por qué nos importa el diálogo? "La cláusula del "NoObstante", "Compromiso significativo" y Audiencias Públicas. Un análisis empático pero crítico", Revista del Centro de Estudios Constitucionales, 5 (2017) pp. 161-193.

Gargarella, Roberto, "Some reservations concerning the judicialization of peace", Harvard International Law Journal. Comment, 59 (2019) pp. 1-19.

Gaviria, Jorge Julián, Inclusión política y gobierno democrático: el problema de la legitimidad del control de constitucionalidad, tesis doctoral, Universidad Carlos III de Madrid, 2017.

González Morales, Felipe, "Pasado, presente y futuro del Sistema Interamericano de Derechos Humanos", en Pablo Santolaya e Isabel Wences (coords.), La América de los Derechos, Madrid, Centro de Estudios Políticos y Constitucionales, 2016.

Hunt, Murray, “Soveringty's Blight: Why Contemporary Public Law Needs the Concept of 'Due Deference'”, en Nicholas Bamforth y Peter Leyland (eds.), Public Law in a Multi-layered Constitution, Oxford, Hart, 2003.

Iglesias Vila, Marisa, "El futuro de los Tribunales Internacionales de Derechos Humanos: ¿Deferencia hacia los Estados o división cooperativa del Trabajo? (Una mirada desde Europa)", en Amalia Amaya, Los desafios constitucionales de la democracia social, Buenos Aires, Libraria, 2019, pp. 151-176.

Lanzaro, Jorge "La izquierda uruguaya. Entre la oposición y el gobierno", Nueva Sociedad, 157 (1998) 154-165.

Lazarus, Liora y Natasha Simonsen, "Judicial Review and Parliamentary Debate: Enriching the Doctrine of Due Deference" en Murray Hunt et al., (eds.), Parliament and Human Rights. Redressing the Democratic Deficit, Oxford, Hart, 2015.

Lessa, Francesca y Natalia Flores Mejía, "Reflexiones sobre el derecho a la verdad y su aplicación en el caso de Uruguay”, en Pablo Galain (ed.), ¿Justicia de Transición? Mecanismos políticos y jurídicos para la elaboración del pasado, Valencia, Tirant lo Blanch, 2016.

Lessa, Francesca, "Justicia más allá de las fronteras", conferencia pronunciada en la Universidad Alberto Hurtado (Chile), noviembre, 2016 b.

Mallinder, Louise, "Combatiendo la impunidad: la erosión gradual de la Ley de Caducidad uruguaya”, en Pablo Galain (ed.), ¿Justicia de Transición? Mecanismos políticos y jurídicos para la elaboración del pasado, Valencia, Tirant lo Blanch, 2016.

Melero, Mariano C., Legalidad como razón pública. Una teoría del constitucionalismo desde el modelo “commonwealth”, Madrid, Centro de Estudios Políticos y Constitucionales, 2020. 
Moreira, Pedro da Silva, Deferencia al legislador: La vinculación del juez a la ley en el Estado Constitucional, Madrid, Centro de Estudios Políticos y Constitucionales, 2019.

Parra, Alejandra, Epistolaridad, literatura y variaciones de la memoria en Juan Gelman y Maurico Rosencof (1956.2007), Tesis Magíster en Literatura Comparada, Universidad Nacional de la Plata, 2020.

Roa Roa, Jorge, Control de constitucionalidad deliberativo. El ciudadano ante la justicia constitucional, la acción pública de inconstitucionalidad y la legitimidad democrática del control judicial al legislador, Bogotá, Universidad del Externado de Colombia, 2019.

Roniger, Luis, "Transitional Justice and Protracted Accountability in Redemocratised Uruguay, 1985-2011”, Journal Latin American Studies, 43(4) (2011) pp. 693-724.

Sanguinetti, Julio María, "La primera respuesta de Sanguinetti a Gelman", 1999. En línea: https://www.pagina12.com.ar/1999/99-11/99-11-07/ pag16.htm

Sauca, José María, "El derecho ciudadano a la Memoria histórica. Concepto y contenido" en José A. Martín Pallín y Rafael Escudero Alday (eds.): Derecho y Memoria histórica, Madrid, Trotta, 2008.

Sauca, José María, "Derecho a la memoria”, en Rafael Escudero Alday (coord.): Diccionario de memoria histórica. Conceptos contra el olvido, Madrid, Catarata, 2011.

Sempol, Diego, "A la sombra de una impunidad perenne. El movimiento de derechos humanos y la ley de caducidad", en Ana Laura de Giorgi (org.), Ley de Caducidad un tema inconcluso. Momentos, actores y argumentos (1986-2012), Montevideo, Trilce, 2013.

Waldron, Jeremy, Law and disagreement, Oxford, Clarendon Press, 1999.

Waldron, Jeremy, The dignity of legislation, Cambridge: Cambridge University Press 1999b. 
